Portland State University

PDXScholar

$10-1-2012$

\title{
Troublesome Concepts and Information Literacy: Investigating Threshold Concepts for IL Instruction
}

Amy R. Hofer

Linn-Benton Community College, hofera@linnbenton.edu

Lori Townsend

University of New Mexico

Korey Brunetti

California State University

Follow this and additional works at: https://pdxscholar.library.pdx.edu/ulib_fac

Part of the Library and Information Science Commons

Let us know how access to this document benefits you.

\section{Citation Details}

Hofer, A. R., Townsend, L., \& Brunetti, K. (2012). Troublesome Concepts and Information Literacy: Investigating Threshold Concepts for IL Instruction. Portal: Libraries \& The Academy, 12(4), 387-405.

This Article is brought to you for free and open access. It has been accepted for inclusion in Library Faculty Publications and Presentations by an authorized administrator of PDXScholar. Please contact us if we can make this document more accessible: pdxscholar@pdx.edu. 


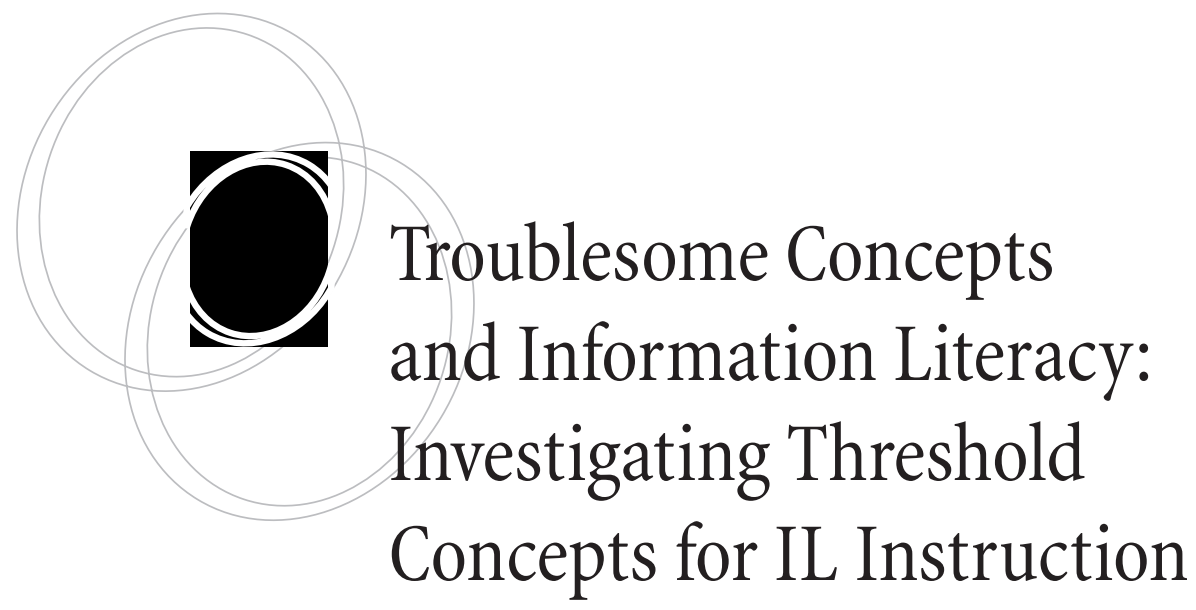

Amy R. Hofer, Lori Townsend, and Korey Brunetti

\begin{abstract}
Librarians regularly encounter students who struggle to understand and apply information literacy concepts. A qualitative survey administered to information literacy practitioners asked about troublesome content and analyzed results using the threshold concepts pedagogical framework first described by Jan Meyer and Ray Land. A threshold concept transforms the learner's view of content and helps integrate previously learned material; threshold concepts are portals that, once traversed, bring insight into how to think and act like a practitioner within a discipline. This project uses the data collected to propose seven threshold concepts for information literacy.
\end{abstract}

\title{
Introduction
}

L ibrarians regularly encounter students who struggle to understand and apply information literacy concepts. From source evaluation to search mechanics, deceptively simple questions betraying a lack of foundational knowledge surface again and again at the reference desk and in the classroom. Far removed from the beginner's perspective, librarians may have forgotten the effort that went into becoming information literate. We find that a pedagogical approach called threshold concepts can help us pinpoint the issues that confound our students, in order to improve our teaching in these areas.

As described by Jan Meyer and Ray Land, threshold concepts are the core ideas and processes in any discipline that define the discipline, but that are so ingrained that they often go unspoken or unrecognized by practitioners. ${ }^{1}$ They are the central concepts that we want our students to understand and put into practice, that encourage them to think and act like practitioners themselves. Meyer and Land propose five definitional criteria for threshold concepts:

portal: Libraries and the Academy, Vol. 12, No. 4 (2012), pp. 387-405.

Copyright $\odot 2012$ by The Johns Hopkins University Press, Baltimore, MD 21218. 
- Transformative-cause the learner to experience a shift in perspective;

- Integrative-bring together separate concepts (often identified as learning objectives or competencies) into a unified whole;

- Irreversible-once grasped, cannot be un-grasped;

- Bounded-may help define the boundaries of a particular discipline, are perhaps unique to the discipline;

- Troublesome-usually difficult or counterintuitive ideas that can cause students to hit a roadblock in their learning. ${ }^{2}$

By looking closely at the places where students struggle most, librarians can use their classroom observations and disciplinary expertise to theorize about where students get stuck and why. What is the underlying concept that students need to grasp in order to cross that learning threshold?

Approaching students as potential disciplinary practitioners is at the core of the threshold concepts approach to teaching. In a biology class, for example, an instructor teaches students how to think like a biologist. The current study foregrounds the idea that students would benefit from understanding some of the information science con-

\section{The current study foregrounds the idea that students would benefit from understanding some of the information science concepts that underlie the practice of librarianship.}

cepts that underlie the practice of librarianship. Coming to agreement on defining threshold concepts for a discipline or practice is a necessary step before putting forward ideas about application; discussing how to teach with threshold

concepts follows this foundational process and is beyond the scope of this paper. This exploratory study queries information literacy instructors about where their students often get stuck, and explores the commonalities that emerge in order to propose seven threshold concepts for information literacy.

\section{Literature Review}

Threshold concepts were first introduced by British educators Jan Meyer and Ray Land as part of the Enhancing Teaching-Learning Environments in Undergraduate Courses research project. ${ }^{3}$ Since then, symposia, books, and a growing body of related publications have refined the idea and explored applications in many disciplines and contexts where learning takes place. ${ }^{4}$ Application of the theory to the practice of teaching is a common theme in the literature. ${ }^{5}$

Because the threshold concept approach leverages disciplinary expertise rather than additional knowledge of educational theory, ${ }^{6}$ it is a good fit for librarians, who may lack formal training in pedagogy. Townsend, Brunetti, and Hofer posit that threshold concepts can help librarians focus on the big ideas underlying information literacy skills in a way that is difficult to achieve with the far-reaching Association of College \& Research Libraries' Information Literacy Competency Standards for Higher Education (ACRL Standards) and their associated learning objectives. They propose four threshold concepts for information literacy: format as process; authority is constructed and contex- 
tual; information as a commodity; and primary sources and disciplinarity. ${ }^{7}$ Several other studies look at whether threshold concepts are useful for information literacy instruction.

Margaret Blackmore describes the results of a series of collaborative workshops whose purpose was to identify threshold concepts for information literacy. Blackmore introduced help desk staff to Christine Bruce's six frames for information literacy education $^{8}$ and Meyer and Land's threshold concepts, in order to create a shared theoretical understanding. The whole group then generated ideas about troublesome content and identified categories in which to cluster their ideas. Smaller working groups attempted to define threshold concepts underlying each area where students get stuck. Blackmore observes that the process of defining threshold concepts leads us to "reconceptualise many of the ways that [we] perceive the information engagement process. Whilst not necessarily the goal, this is a valuable byproduct of the process of identifying threshold concepts." ${ }^{\prime 9}$

This study shares the same objective as Blackmore's, that of identifying information literacy threshold concepts, but employs a different approach. Blackmore's methodology had the benefit of many practitioners' input into formulating threshold concepts, but her participants were introduced to threshold concepts only recently; in the present study, threshold concepts were formulated solely among the three authors, with the benefit of a long-term study of the literature to inform the discussion. Not surprisingly, the results differ, although the over-

\section{This raises the question of whether there is a single set of threshold concepts for information literacy.}

raises the question of whether there is a single set of threshold concepts for information literacy. With such a new area of inquiry, different points of view are bound to emerge and we hope that further research will consider and perhaps resolve such questions.

Phil Yorke-Barber et al. compare how experts and students view research, ${ }^{10}$ an approach first proposed by Peter Davies as an avenue for identifying threshold concepts. ${ }^{11}$ Denyse B. Rodrigues and DeNel Rehberg Sedo ask whether Second Life is an effective environment for teaching information literacy. ${ }^{12}$ Both of these studies understand information literacy - as a whole - to be a threshold concept. However, the present study documents research undertaken from the perspective, shared by Blackmore, that information literacy is a body of knowledge for which there exist specific threshold concepts. ${ }^{13}$ By way of analogy, "economics" is not a threshold concept; but "opportunity cost" is a threshold concept within the discipline of economics. ${ }^{14}$

Defining threshold concepts for information literacy brings up a potentially elusive characteristic of threshold concepts: that, per Meyer and Land, they may be bounded by a discipline. For example, can "citation" be an information literacy threshold concept—as Yorke-Barber et al. propose-when it is needed in every discipline ${ }^{15}$ Which discipline bounds "proficiency in the Second Life environment" —one of Rodrigues and Sedo's threshold concepts? ${ }^{16}$ How can Blackmore's thresholds relating to time management, academic acculturation, and affect be understood as unique and specific to information literacy? ${ }^{17}$ Clearly there is productive work to be done in theorizing how threshold concepts may be applied in an interdisciplinary context. 
When Naomi Irvine and Patrick Carmichael conducted a study comparing the ways in which faculty from three disciplines developed candidate threshold concepts for their own fields, they found that participants in an interdisciplinary workshop environment chose concepts that "exemplify discipline-specific conceptual frameworks."18 In other words, defining threshold concepts for a

In other words, defining threshold concepts for a discipline or area of practice opens fruitful discussion about disciplinary identity. discipline or area of practice opens fruitful discussion about disciplinary identity. We found that discussing threshold concepts can advance the discourse about the boundaries of information literacy as an area of practice.

\section{Methodology}

The goals of this research were to:

- Identify student stumbling blocks in information literacy through surveying information literacy instructors

- Identify potential threshold concepts by analyzing these stumbling blocks for the underlying broad transformative themes using the threshold concept criteria.

As John Creswell states, analyzing qualitative data "is an eclectic process" with the aim of generating fresh insight into the problem being studied while building a fuller understanding. ${ }^{19}$ In this case, it is not a goal to prove quantitatively that all librarians agree about specific troublesome concepts. Rather, we seek to identify areas for deeper exploration and potential application of the threshold concept framework.

\section{Survey Instrument}

We used an open-ended qualitative survey to query information literacy instructors. The survey was conducted using SurveyMonkey. Invitations to participate were posted in September 2010 to three listservs: ALA's Information Literacy Instruction Listserv, Australian Library and Information Association User Education Listserv, and the JISC Information Literacy Listserv. The survey invitation was reposted until we received enough responses to reach saturation. Saturation, as defined by Christine Daymon and Immy Holloway, is "a state where no new data of importance to the specific study and developing theory emerge and when the elements of all categories are accounted for." 20 In our case, saturation was indicated by seeing the same troublesome concepts identified repeatedly by different respondents.

The survey asked the following:

Please identify three key concepts or big ideas that your students struggle to understand.

Describe each, then answer the following:

What do you think is the main reason your students struggle with this concept? As a

librarian, how does your approach to this idea/ concept differ from that of your students?

We did not introduce practitioners to the threshold concept framework as part of the survey. This is because- as is frequently pointed out in the threshold concept literature- 
threshold concepts are an idea that can take some time to fully grasp (in other words, threshold concepts are a threshold concept). ${ }^{21}$ We often found that as we revisited Meyer and Land's position paper to test our ideas according to their definitional criteria, what had looked like a promising threshold concept, in fact, wasn't. Therefore, we could not expect our respondents to absorb an entire pedagogical theory in a ten-minute survey.

However, librarians were asked to comment on student struggles in order to encourage them to elaborate on the troublesome nature of the concept. We also asked them to differentiate their understanding from the student approach because one of the primary features of a threshold concept is its tacit nature among experts and its simultaneous inaccessibility to beginners. We hoped that making this dichotomy explicit to participants and asking them to explain it would help to identify threshold concepts underlying the troublesome content.

\section{Coding}

Coding began as soon as the first responses were received and saturation was reached well before the final responses were processed. Responses were initially coded using free text tags to describe the content. At first, the coding process was carried out by all three researchers as a group at the same time. After agreement was reached on a basic set of tags, the process was carried out in parallel, with periodic group sessions where each response and its tags were reviewed together to confirm the coding done by individuals. Thus, a group of agreed-upon tags was generated for each entry. ${ }^{22}$ An example response and associated tags can be seen in Figure 1.

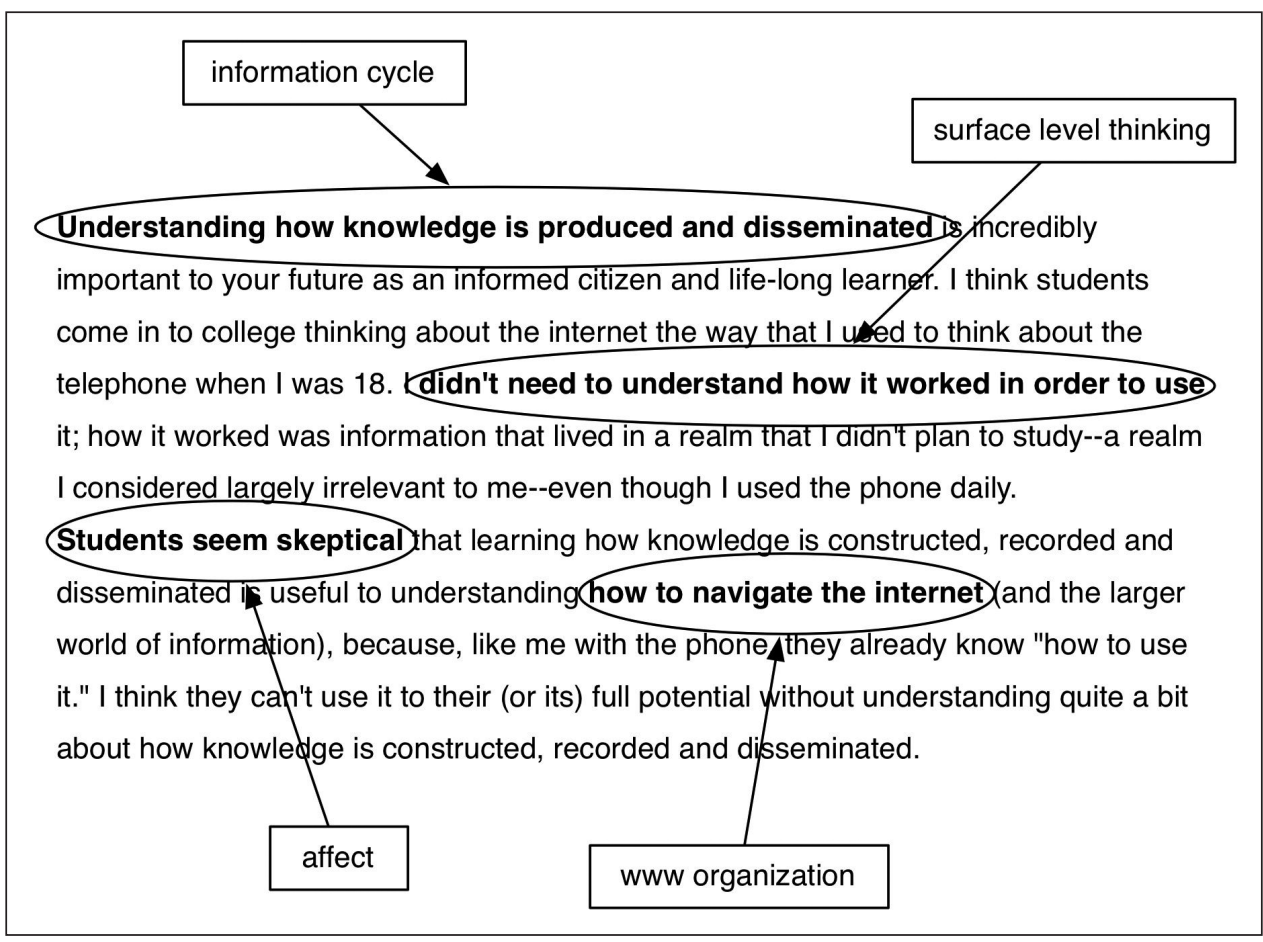


The complete list of tags generated can be seen in Figure 2.

\begin{tabular}{|c|c|c|}
\hline Codes & & \\
\hline $\begin{array}{l}\text { affect } \\
\text { authority } \\
\text { boolean } \\
\text { call numbers } \\
\text { citation } \\
\text { commodity } \\
\text { controlled vocabulary } \\
\text { cycle of information } \\
\text { database structure } \\
\text { databases } \\
\text { disciplinarity } \\
\text { expert } \\
\text { format } \\
\text { google }\end{array}$ & $\begin{array}{l}\text { information quilting } \\
\text { intellectual property } \\
\text { keyword searching } \\
\text { library arcana } \\
\text { library research process } \\
\text { library vs. google } \\
\text { metadata } \\
\text { objectivity } \\
\text { one source focus } \\
\text { originality } \\
\text { plagiarism } \\
\text { power of print } \\
\text { relevance } \\
\text { research purpose }\end{array}$ & $\begin{array}{l}\text { research questions } \\
\text { scholarly } \\
\text { search construction } \\
\text { search terms } \\
\text { searching } \\
\text { source evaluation } \\
\text { surface level thinking } \\
\text { tool evaluation } \\
\text { topic development } \\
\text { troublesome language } \\
\text { web sources } \\
\text { www organization }\end{array}$ \\
\hline
\end{tabular}

As coding proceeded, we wrote memos about potential overarching themes and any problematic content or codes. For example, our memo for "surface level thinking" reads: "Characterized by an unwillingness to go to or an unawareness of a deeper level-an unwillingness to change your strategy or engage critically. Tendency to focus on good/ bad, black/ white-ignoring context."

After the initial round of coding, similar tags were merged and then the codes were clustered into themes, representing the strongest ideas that emerged from the data. For example, the "expert," "objectivity," and "source evaluation" codes were grouped under the theme "authority." Some tags belonged in more than one theme; for example, "source evaluation" was also appropriate under the "format" theme. The themes were then grouped together into three general categories, which helped us map them to existing information literacy standards. For example, the themes "Web organization," "database structure," and "metadata" were clustered under the category "finding information." Finally, two meta-themes emerged from the data as a whole, providing a backdrop for the themes and categories that emerged.

\section{Theoretical Framework}

Throughout the coding process, the content of the responses and associated tags, themes, and categories was under continuous discussion in order to identify potential threshold concepts. We understand the threshold concept framework as directly relating to the five definitional criteria identified by Meyer and Land. Each hypothesized threshold concept was assessed according to these criteria. 
Identifying stuck places is a starting point, but theorizing a threshold concept involves going further by asking what transformative, integrative concept must be grasped in order for students to move forward from that point. Analyzing our codes and clustering them into themes helped us articulate the tacit disciplinary knowledge that underlies these struggles. The process of defining threshold concepts applies Meyer and Land's criteria to an analysis informed by practitioner experience and judgment.

Several of the threshold concepts in this paper were proposed prior to this study. The data collected here confirmed the ubiquity of the trouble spots that sparked our original threshold concepts. Responses also encouraged us to explore other areas, some new, and some that we suspected were fertile ground for threshold concept development.

We also view information literacy threshold concepts as distinct from the already well-understood tenets of information literacy instruction as defined by ACRL and similar organizations in the U.K. and Australia (SCONUL, ALIA). The ACRL standards comprise a mix of processes, concepts, big ideas, and minute details. They do not offer consistent guidance for instructors on teaching priorities. Threshold concepts are, by nature, prioritized content because they are the foundational concepts that students have trouble with but need to grasp in order

The ACRL standards comprise a mix of processes, concepts, big ideas, and minute details. They do not offer consistent guidance for instructors on teaching priorities. to move forward with their learning. Query-

ing practitioners about their empirical observations of students' significant challenges pinpointed current student trouble spots, whether these are reflected in existing standards or not. Moreover, simply analyzing the ACRL standards with an eye toward potential threshold concepts would bypass the input of disciplinary practitioners who apply the ACRL standards on the front lines.

\section{Limitations}

The anonymous online survey format, chosen for its ease of deployment and access for international respondents, was limited by its static, non-interactive nature. When responses were ambiguous or particularly insightful, there was no opportunity for the authors to ask follow-up questions with participants to clarify or investigate further.

A limitation of soliciting responses from a listserv is that our respondents were selfselecting. Survey fatigue may be a factor that limits responses to this type of solicitation. We did not conduct a pilot survey to test our questions because of concerns that it would further limit interest in responding to the actual survey.

Another potential limitation of this study is its reliance on data gathered from practitioners with worldviews informed by common pedagogical standards of practice. Librarians' use of standards tends to structure their thinking about information literacy and this influences what and how they choose to teach. Responses, then, may reflect what participants already teach at the desk or in the classroom, rather than fully mapping potential student pitfalls in the current information environment.

It is also possible that a different group of analysts would have used the same data to reach different conclusions about possible information literacy threshold concepts. The 
authors have been working on developing threshold concepts for information literacy, through discussion, presentation, and writing, over several years and interpreted the data from the present survey accordingly.

\section{Results}

\section{Overview}

Fifty-nine librarians participated in the survey, for a total of 152 separate responses (each respondent was asked to identify three concepts, but some only identified two). The data can be reviewed at the University of New Mexico Institutional Repository. ${ }^{23}$

Respondents teaching credit-bearing classes constituted the majority of our respondents (59.3 percent); 40.6 percent did not have dedicated information literacy courses. A slight majority (54.3 percent) had fewer than three years of experience teaching, with 14.2 percent reporting three to five years, fifteen percent reporting five to ten years, and 16.5 percent with ten or more years. We note that our use of qualitative methodology precludes deriving correlations between demographic information and the responses received.

The results of our survey are organized by meta-themes, themes, and categories, as seen in Figure 3.

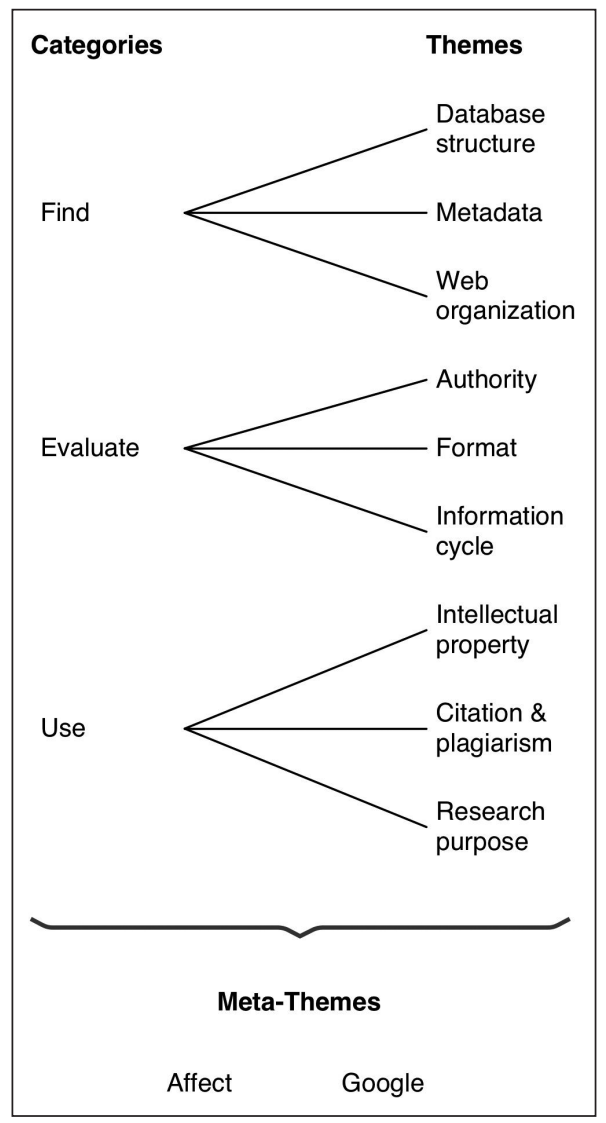


The threshold concepts we propose based on these results are developed in the discussion section, below.

As expected, the influence of the ACRL Information Literacy Standards was readily apparent in the survey responses. These comprehensive standards define both LIS education and academic libraries' instructional programs. It follows that practitioners would map their perceptions of student challenges in information use to these existing schema, and our three categories reflect a similar professional orientation.

\section{Meta-Themes}

The meta-themes that emerged from the data are relevant to all of the categories and themes that we identified, though they did not lead us to specific threshold concepts and are not reflected in accepted standards documents such as ACRL's. One meta-theme has to do with the impact of Google, while the second deals with student affect or attitude toward research.

\section{Meta-Theme: Google}

Is Google making us "stoopid," as Nicholas Carr famously asked in his Atlantic Monthly cover story? ${ }^{24}$ Google was frequently used by respondents as a shorthand for Web sources in general, and it appeared in many responses relating to searching, source evaluation, and databases, for example:

They seem to see information as flat, as coming all from one place, Google :)

The post-Google landscape was inseparable from every theme emerging in this study, which is stunning when one considers that Google has been around for just a little over a decade. As it happens, the ACRL Standards, adopted in 2000, are nearly the same vintage. This is notable because much of the troublesome content identified by the survey participants will be familiar from the ACRL standards, but at the same time, everything in those standards is perceived as more confusing and harder to teach in the Google era.

Many respondents made explicit "us/them" comparisons between libraries and Google. The comments reflect admiration for Google's efficiency and user-friendliness, but bemoan how it has complicated the research process by setting up unrealistic expectations and even making library sources seem arcane. As one Australian respondent wrote:

With Google you can bung a few words in and get some results when they get to the databases with peer reviewed content they don't find anything and are surprised.

Further, libraries suffer from a visibility problem related to profound misunderstandings about Google, as in this response:

I think the main reason students struggle is that they see information resources as all being one amorphous thing, and can't grasp that it's actually lots of different things (I'm aware of recent research done in the US that showed that university students think the Google [sic] actually creates all the websites that it indexes, evidence of a total lack of awareness of how the Web actually works). 
Before Google, the library was the beginning and end of available information for most students, and the library was filled with pre-vetted materials conveniently sorted into the various formats. For the most part librarians did the evaluation, while students could focus on whether a source was relevant to their research. Now students encounter formats in the wild, with little guidance on their nature, source, or authorship. They must act as amateur selectors. This reality disputes the oft-heard limitation, "we don't want to make little librarians" out of our students. In a sense, the Web requires this of them.

\title{
Meta-Theme: Affect
}

Many librarians commented on the attitudes or emotions of students in relation to research, the library, or academia. That students often experience a negative emotional response when struggling with difficult content is not surprising. Some comments reflect librarians' frustrations as well, as in this example:

\begin{abstract}
They don't ask what their information needs are or what type of information they may need to answer the questions. Students have problems with this because they are lazy and incurious and think they can just throw their thesis idea into a search box and get relevant results.
\end{abstract}

...they seem to get frustrated if it's not easy...

Along similar lines, respondents also pointed out that students are poor judges of their own capabilities. Often this inaccurate student self-perception is reinforced by pervasive messages about young people and technological proficiency:

They think they know how to search. They believe the rumors that they are tech savvy and are expert searchers.

I think that students struggle with the notion that they are actually required to expend some mental effort in using resources because the mass media is constantly telling them how Web savvy they are, with tutors and parents and commentators (i.e. not researchers) saying that young people (and I'm assuming here that most students fall into the 18-25 year old group) have, by definition, excellent media handling skills.

On the one hand, the attention to student affect shows the extent to which librarians are sensitive to non-content barriers to learning. Having a good attitude (positive affect) is not part of the content of information science, nor is it a characteristic of an information literate student as defined by ACRL. On the other hand, the places where students exhibit negative affect can pinpoint where to look for the underlying thresholds that students need to cross in order to get un-stuck.

\section{Category: Finding Information}

The first category relates to ACRL Standard \#2: "The information literate student accesses needed information effectively and efficiently." Respondents pointed to students' difficulty finding information, an issue that encompasses both deciding where to search and how to use search tools.

Three themes emerged within this category. 


\section{Theme: Metadata}

Librarians reported that students are unaware of underlying metadata structures and how they can be leveraged to improve search efficacy. Several noted that students were confused by database and catalog records, expecting all digital information to be full-text:

Students...don't understand that when executing searches that they are not searching the full-text of an item, but what they are really searching is just data about data in order to get to the full-text.

Respondents singled out controlled vocabularies as a specific metadata structure that perplexes students:

In the era of the keyword, the concept of vocabularies not tied to words in titles, etc. is very foreign to most students.

These observations suggest that students, accustomed to keyword searching, forfeit relevance for familiarity and convenience.

\section{Theme: Web Organization}

Frequent Googling does not translate into student proficiency with Web search or their understanding of what "the Web" actually is. Student misunderstanding of how pages are discovered and returned to a user came up frequently. As one respondent noted:

Students see "the Web" as a giant flat landscape. They have problems conceptualizing the pieces contained within.

Unsurprisingly, their lack of awareness regarding what the Web is (and is not) feeds their confusion about how Web search engines differ from library databases, what they find through these portals, and why the same search techniques will not yield the same results:

To them, Google is the same as a library database—-they should work the same.

Several respondents noted student reluctance to move beyond a single search tool -typically Google:

Students seem to have implicit trust in the power of Google, seeing the Net as a library and Google as its intelligent catalog, choosing the best resources for the user. That trust needs to be tempered by reality.

Of course, progressing beyond one's comfort zone is challenging for any researcher, let alone for students just beginning to understand the online information landscape.

\section{Theme: Database Structure}

Respondents frequently cited the content, organization, and mechanics of database search as stumbling blocks. The database structure theme is closely related to students' confusion in regard to metadata and Web organization, but uniquely addresses the struggles students encounter in the face of faceted search options, limiters, and multiple search boxes: 
Search boxes! They seem to feel that they can pour their hearts out into them and have no idea of separating concepts.

Students often see databases as Google-like. Plug in the keywords and choose the first five results. They need to be shown how to manage results, narrowing their focus, and eliminating irrelevancies.

Respondents reported that their students had little awareness of what was being searched within a particular database (both the indexed fields and the content itself). They also noted that Boolean logic is problematic for students.

Boolean—Students are used to a single search interface ala Google...

Part of the problem seems to lie in the similarity of the simple search box across interfaces. Students see a box and assume they know how to use it, just like Google.

\section{Category: Evaluating Information}

Another group of themes that emerged from the data can be broadly classified under the category of "evaluating information," which relates to ACRL Standard \#3: "The information literate student evaluates information and its sources critically and incorporates selected information into his or her knowledge base and value system."

There are three themes explored within this category. A fourth theme that emerged strongly was literacy in the sense of reading and writing skills. While the ability to read is, obviously, crucial to evaluating a source, it lies outside the subject domain of library and information science and therefore is not included here.

\section{Theme: Formats}

Many responses indicated that students tend to see all information as one amorphous mass rather than as specific sources produced by specific communities. Further, differentiating formats is more difficult when we encounter everything online, for example:

Students see "the Web" as a giant flat landscape. They have problems conceptualizing
the pieces contained within. Journal articles look the same as newspaper articles look
the same as web pages.
There are more source types than article, website, book, and video. You need to be able
to recognize many different types of sources and be able to find many different types of
sources in order to succeed in the academic environment. Visual cues that informed my
and most of my peers' understanding about writing vs. other forms of communication did
not inform our students' understanding about communication to nearly the same degree...

The Web makes it very difficult to distinguish traditional formats, such as books, journal articles, newspapers, and magazines, from one another. It also adds a host of Web-specific formats, like blogs, commercial websites, and governmental websites, all of which appear in a browser on a computer screen.

\section{Theme: Authority}

Respondents also cited the difficulty students encounter when evaluating a source's authority. According to respondents, when students see something written, whether 
on the page or on the screen, they often assume the author is qualified to write about it. For example, students had trouble with:

The idea of quality information sources. Some of our "digital natives" are shockingly naive about what they read on the Internet, and have little idea of quality control of sources.

Evaluating the credibility of the author and source often means you need to look beyond the source itself. They have too much confidence in search tools-Google and in what is written on the page or website. They don't want to take time to vet sources.

How to determine authority in a source when they are not experts. I think they are still negotiating their understanding of how we can trust when we realize nothing is absolute.

If students do look for credentials, they are often hard to locate or nonexistent. Moreover, as beginners, students are poorly prepared to evaluate the information through other means. Adding to the confusion, sites like Wikipedia are eroding the traditional model of authority:

Understanding the quality of different types of information-a blog post vs a scholarly article. Today's online culture stresses all opinions are right/appropriate/valid.

\section{Theme: Information Cycle}

Many respondents pointed to the need for students to understand the way in which information is created and published, often referred to as the information cycle:

Information and knowledge is not a random sandpile, but a developed landscape of communities which have the information they need. So they may need to go well beyond a generic search engine to find sources. Students don't yet see the structures of scholarly communication.

...Students seem skeptical that learning how knowledge is constructed, recorded, and disseminated is useful to understanding how to navigate the Internet (and the larger world of information), because, they already know "how to use it." I think they can't use it to their (or its) full potential without understanding quite a bit about how knowledge is constructed, recorded, and disseminated.

An advanced level of evaluation involves examining information through the disciplinary lens. This requires understanding the way information is created in a discipline, the types of questions asked by researchers, and the methodologies used to answer them, for example:

That when you critically review or assess research material at the university level, the students should be looking at the quality of the research method, argument, conclusions, innovation, (individually and also in a broader relation to other materials on the same subject) rather than just superficially stating their unsupported opinion about their own lack of understanding of terminology, the difficulty in reading, their feelings, ideology, or even [high school] level ways of assessing documents (author, source, currency, etc).

This response also highlights the lack of preparedness many undergraduates exhibit. They come to college precisely to learn the disciplinary knowledge they need in order to become expert evaluators, but may not be gaining the required skills. 


\section{Category: Using Information}

The final category is using information, in the sense of intellectual property and attribution. It relates to ACRL Standard \#5, "The information literate student understands many of the economic, legal, and social issues surrounding the use of information and accesses and uses information ethically and legally." In their responses, librarians wrote about the complexity of using information in a digital culture.

In the context of our research, this category is intertwined with evaluation, as themes such as the cycle of information and authority certainly come up in discussions of ethical information use. What also emerged in these responses were, again, a few themes that are not exclusively in the domain of information studies, particularly academic writing skills and overall literacy. Clearly, students need to be able to read and write well in order to properly attribute, synthesize sources, and produce their own work, but this is true in all disciplines.

Three information literacy related themes were identified within this category.

\section{Theme: Citation and Plagiarism}

It is not surprising to find citation and plagiarism singled out repeatedly as trouble spots. Teaching citation skills often falls to librarians, but like academic writing skills, it is not precisely ours to teach. However, this theme does concern concepts that are central to information literacy.

For example, some comments connected reading citations with issues of disciplinarity:

How to connect a body of literature and follow up on citations

While other comments connected this theme with format and the problem of Google making content seem "flat":

How to read a citation and understand what type of publication it represents-journal article, book, etc... Many are used to getting all information from one flat source-Google.

They have a hard time with understanding basic types of resources and how that translates into citation. For example what is the difference between a peer reviewed article and a government document or a newspaper or website etc and how do the different components of these translate into a citation?

There was a clear pattern in our citation-themed responses that many students lacked an understanding of the underlying purpose of citation, as in this response:

APA Citation style. Too many rules, not enough understanding of why APA is the way it is.

Citation procedures may seem, as Stanley Fish observed, like the rules of golf-complex and obscure for no good reason..$^{25}$ As with many stumbling blocks, this problem has only been exacerbated by extensive use of digital sources.

\section{Theme: Intellectual Property}

With the perception that all information is "free on the Web," students face increasingly confusing rules and situations relating to information production, information stakehold- 
ers, and the information marketplace. Added to this, intellectual property policy and law have fallen far behind technological advances that have changed common-sense ideas about what is mine and what is yours, as in this example:

Intellectual property-the culture of cut and paste. Most understand the basics of putting quotes around copied text, but they are less sure of paraphrasing, and guidelines for using images. Many also don't understand fair use - they use information freely in college, but when they go into a professional position they can get into serious trouble if they are not in the habit of getting copyright permissions. They also lack a big-picture understanding of the implications of intellectual property laws and the impact they will have on their futures in terms of becoming producers of intellectual property.

Given these considerations, perhaps students' confusion when they are prompted to buy an article on the Web, or puzzlement at the mention of fair use, is perfectly understandable, as outlined in this response:

Understanding the information economy... Librarians understand how different types of information are produced and disseminated; we also understand that there are a lot of players in the information market (library vendors, publishers, authors, Google, etc.).

Students don't see these "players," and their fuzziness around ownership and production issues may reflect confusion over digital information in the culture at large. Meanwhile, librarians may let the mechanics of plagiarism and citation stand in for the bigger issues having to do with information ethics and the information economy, such as privacy, freedom of speech, and constraints on information sharing. If these larger concepts remain tacit, students are unlikely to connect them to the procedures they must learn in order to follow the rules of academia.

\section{Theme: Research purpose}

Respondents noted that students fail to connect their research efforts with a purpose greater than locating and stitching together sources:

Students generally view research as an information compilation exercise rather than a problem solving venture that uses information as a tool to deal with an issue.

The use of sources should lead to some original thought on their part, not just a mash-up of what they found.

The complexity of the academic research process, characterized by critical inquiry, careful weighing of available evidence, and ultimately the production of new knowledge, is very hard to teach in any discipline. The idea that research can be used to solve problems may be unfamiliar to students and, predictably, reveals problems with topic development and thesis formation:

They should not have their thesis fully formed before they do any research. They just don't have much experience researching or writing, and this kind of writing is hard.

Narrowing a topic and refining a research question. Students are geared toward collecting bits of information and reporting —not toward learning something new. 
Like the teaching of citation, educating students about the purpose of academic research does not fall to librarians alone. However, the frequency with which our respondents alluded to the purpose of research suggests that this is significant trouble spot, and one with a great impact on how students use information.

\section{Discussion: Threshold Concepts}

Patterns in the survey responses revealed common trouble spots pointing to potential information literacy threshold concepts. Drawing on the experience shared by the respondents, as well as previous analysis of information literacy instructional content, the authors propose the following threshold concepts for information literacy:

- Metadata=findability

- Good searches use database structure

- Format is a process

- Authority is constructed and contextual

- "Primary source" is an exact and conditional category

- Information as a commodity

- Research solves problems

The proposed threshold concepts are sketched in this section. While beyond the scope of this paper, the authors note that the next step from a pedagogical standpoint is to make curricular changes that surface the teaching and learning of these concepts and then to assess student learning in these areas.

\section{Metadata $=$ Findability}

Understanding the nature and purpose of metadata (information about information) relates to the principle of "aboutness" in the organization of information. Metadata

Metadata makes information findable through its orderly description of the qualities of that information. makes information findable through its orderly description of the qualities of that information. Students who understand the function of metadata and recognize it in, for example, controlled vocabularies, URLs, indices, and citations can better track relevant information through complex networks.

\section{Good Searches Use Database Structure}

Teaching the mechanics of search engines and database search fields directly counters efforts to reduce all search to a single, innocuous box. Yet the complexity of these search tools is, ultimately, explanatory. Having to use multiple search fields, controlled vocabularies, and Boolean logic teaches the user how to get the most out of a database, know its limits, and, perhaps most important, conceive of information sets as something with an organization and underlying system, rather than a mysterious cloud of data that serves up "good enough" information on command. 


\section{Format as a Process}

What makes a book a book and a newspaper article a newspaper article has nothing to do with how one accesses it (print/ digital), but with the process that went into creating it. Understanding this principle helps students navigate the information they find online and evaluate it according to the process underlying its creation, rather than by a set of memorized, constantly changing, inconsistent characteristics.

\section{Authority is Constructed and Contextual}

Once students understand that authority doesn't just exist, but is constructed-and what constitutes authority changes depending on the context-they begin to understand that true objectivity is unattainable and authority is not monolithic.

\section{"Primary Source" is an Exact and Conditional Category}

Primary and secondary sources are created and used differently in different disciplines. The same source could be considered primary material in one context and shift to secondary when viewed through a different disciplinary or temporal lens. Understanding this leads to a deeper understanding of the purpose of research and the generation of new knowledge.

\section{Information as a Commodity}

Thinking about information in economic terms positions students to better understand their responsibilities as consumers-and hopefully producers-of information. This understanding is key because it answers the "why" question behind academic practices that may otherwise seem mystifying or pointless, such as properly attributing a source.

\section{Research Solves Problems}

That research has a purpose beyond the compilation of information seems obvious to librarians and academics, but beginning scholars struggle to see the point of the generic "research" paper because it is removed from their real-world context of information retrieval and use. Understanding the role of research in academia helps students understand research as a nonlinear, integrative process of finding and using information.

\section{Conclusions}

This study follows the lead of other threshold concept researchers who gather their colleagues' perspectives on student "stuck places" in learning about their various disciplines. Future research directions include investigating student outcomes in relation to learning thresholds in information literacy as well as refining the set of threshold concepts for information literacy by seeking the perspective of experts in the field.

As a theoretical frame, threshold concepts can help librarians devise targeted curricula by prioritizing trouble spots in a way that professional standards documents do not. The proposed threshold concepts articulate understandings about information 
science that are plain to experts but may confound novices. Learners who cross these thresholds are well positioned for academic inquiry, and primed to master many of the specific objectives and outcomes found in standards documents. Continuing research will help us develop a comprehensive threshold concept-based instruction theory for information literacy.

Amy R. Hofer is Distance Learning Librarian at Portland State University, e-mail ahofer@ pdx.edu; Lori Townsend is Data Librarian for Social Sciences and Humanities at University of New Mexico,e-mail lt@unm.edu; and Korey Brunetti is Reference and Instruction Librarian at California State University, East Bay; e-mail korey.brunetti@csueastbay.edu.

\section{Notes}

1. Jan Meyer and Ray Land, "Threshold Concepts and Troublesome Knowledge: Linkages to Ways of Thinking and Practising Within the Disciplines," ETL Project Occasional Report 4 (Edinburgh: Enhancing Teaching-Learning Environments in Undergraduate Courses Project, 2003): 9, http://www.etl.tla.ed.ac.uk/docs/ETLreport4.pdf (accessed 29 January 2012).

2. Ibid, $4-5$.

3. Ibid.

4. “Threshold Concepts: Undergraduate Teaching, Postgraduate Training, and Professional Development, A Short Introduction and Bibliography," Mick Flanagan, last modified 25 November 2011, http://www.ee.ucl.ac.uk/ mflanaga/thresholds.html (accessed 29 January 2012).

5. Ray Land et al., "Threshold Concepts and Troublesome Knowledge (3): Implications for Course Design and Evaluation," in Improving Student Learning: Diversity and Inclusivity, Proceedings of the 12th Improving Student Learning Conference, ed. Chris Rust (Oxford: Oxford Centre for Staff and Learning Development), http://wwww.brookes.ac.uk/services/ocsld/isl/ isl2004/abstracts/conceptual_papers/ISL04-pp53-64-Land-et-al.pdf (accessed 17 June 2012).

6. Jan H.F. Meyer and Ray Land, "Stop the Conveyor Belt, I Want to Get Off," Times Higher Education Supplement 1807, 17August 2007, http://www.timeshighereducation.co.uk/story.asp? se ctioncode $=26 \&$ storycode $=90288$ (accessed 29 January 2012).

7. Lori Townsend, Korey Brunetti, and Amy R. Hofer, "Threshold Concepts and Information Literacy," portal: Libraries and the Academy 11, 3 (2011).

8. Christine Bruce, Informed Learning (Chicago: Association of College and Research Libraries, 2008).

9. Margaret Blackmore, "Student Engagement with Information: Applying a 'Threshold Concept' Approach to Information Literacy Development," (paper, 3rd Biennial Threshold Concepts Symposium: Exploring Transformative Dimensions of Threshold Concepts; Sydney, Australia, 1-2 July 2010), 9-10.

10. Phil Yorke-Barber et al., "Light Bulb Moments: Identifying Information Research Threshold Concepts for Fourth Year Engineering Students," in Nineteenth Annual Conference Proceedings of the Australasian Association for Engineering Education: To Industry and Beyond, ed. Llewellyn Mann, Adam Thompson, and Prue Howard (Yeppoon, Queensland, 7th10th December 2008) http://espace.library.uq.edu.au/eserv/UQ:159735/aaee08_submission_T1C2. $p d f$ (accessed 29 January 2012).

11. Peter Davies, "Threshold Concepts: How Can We Recognise Them?" in Overcoming Barriers to Student Understanding: Threshold Concepts and Troublesome Knowledge, ed. Jan H.F. Meyer and Ray Land (London: Routledge, 2006).

12. Denyse B. Rodrigues and DeNel Rehberg Sedo, "Experiencing Information Literacy in Second Life," Partnership: the Canadian Journal of Library and Information Practice and Research 3, 1 (2008), http://journal.lib.uoguelph.ca/index.php/perj/article/view/426/860 (accessed 29 January 2012). 
13. Townsend, Brunetti, and Hofer, "Threshold Concepts and Information Literacy," 858.

14. Meyer and Land, Threshold Concepts and Troublesome Knowledge: Linkages.

15. Yorke-Barber et al., "Light Bulb Moments," 5.

16. Rodrigues and Sedo, "Experiencing Information Literacy," 3.

17. Blackmore, "Student Engagement with Information," 5, 7-8.

18. Naomi Irvine and Patrick Carmichael, "Threshold Concepts: A Point of Focus for Practitioner Research," Active Learning in Higher Education 10, 2 (2009): 112.

19. John W. Creswell, Educational Research: Planning, Conducting, and Evaluating Quantitative and Qualitative Research, (Upper Saddle River, NJ: Pearson/Merrill Prentice Hall, 2008), 234.

20. Christine Daymon and Immy Holloway, Qualitative Research Methods in Public Relations and Marketing Communications, $2^{\text {nd }}$ ed. (New York: Routledge, 2011), 368.

21. James Atherton, Peter Hadfield, Renee Meyers, "Threshold Concepts in the Wild," (expanded version of a paper presented at Threshold Concepts: From Theory to Practice Conference, Queen's University, Kingston Ontario, 18-20 June 2008), http://www.bedspce.org. uk/Threshold_Concepts_in_the_Wild.pdf(accessed 18 June 2012).

22. Earl R. Babbie, The Practice of Social Research, $11^{\text {th }}$ ed. (Belmont, CA: Thomson Wadsworth, 2006).

23. University of New Mexico Institutional Repository, http://repository.unm.edu.

24. Nicholas Carr, "Is Google Making Us Stupid?," Atlantic Monthly 302, 1 (July 2008): 56-63.

25. Stanley Fish, "Plagiarism is Not a Big Moral Deal," Opinionator (blog), New York Times, August 9, 2010, http://opinionator.blogs.nytimes.com/2010/08/09/plagiarism-is-not-a-big-moraldeall. 